\title{
The New Normal of Medical Education - Challenges and Opportunities
}

\author{
Karunathilake, I.M. ${ }^{1}$, Dissanayake, V.H.W. ${ }^{1}$, Yasawardena, $S .^{2}$, Abegunawardena. A. ${ }^{3}$, \\ Raviraj, S. ${ }^{4}$, Wijesinghe. P.S. ${ }^{5}$, Anthony, A.A. ${ }^{6}$, Wijesinghe, R.A.N.K. ${ }^{7}$, Bowatte, S. ${ }^{8}$, \\ Wickramaratne, N. ${ }^{9}$, Pathirana, K.D. ${ }^{10}$, Pilapitiya, S. ${ }^{11}$, Edirisinghe, S. ${ }^{2}$, Hettiarachchi, D. ${ }^{1}$, \\ Kohombange, $C .^{12}$ \& Olipeliyawa, $A .{ }^{1}$
}

\section{Introduction}

In the wake of the COVID-19 pandemic, Medical Education worldwide has seen some remarkable changes. The digital transformation already seen in Medical Education has progressed rapidly and the profound effect of the current situation may have an everlasting impact on how future doctors are educated (Rose, 2020). Social distancing will be the new norm as it is the most effective preventive strategy pending an effective treatment or the development of a vaccine or both (Del Rio \& Malani 2020). This is indeed a transformative juncture to learn and apply new methods and practices.

${ }^{1}$ Faculty of Medicine, University of Colombo, Sri Lanka.

${ }^{2}$ Faculty of Medical Sciences, University of Sri Jayawardenepura, Sri Lanka.

${ }^{3}$ Faculty of Medicine, University of Peradeniya, Sri Lanka.

${ }^{4}$ Faculty of Medicine, University of Jaffna, Sri Lanka.

${ }^{5}$ Faculty of Medicine, University of Kelaniya, Sri Lanka.

${ }^{6}$ Faculty of Health-care Sciences, Eastern University of Sri Lanka.

${ }^{7}$ Faculty of Medicine, General Sir John Kotelawala Defence University, Sri Lanka.

${ }^{8}$ Faculty of Medicine, Wayamba University of Sri Lanka.

${ }^{9}$ Faculty of Medicine, Sabaragamuwa University of Sri Lanka.

${ }^{10}$ Faculty of Medicine, University of Ruhuna, Sri Lanka.

${ }^{11}$ Faculty of Medicine and Allied Sciences, Rajarata University of Sri Lanka.

${ }^{12}$ Ministry of Health, Sri lanka.

Corresponding Author: Professor Indika Karunathillake Head, Department of Medical Education,

Head, WHO Collaborating Centre for Medical Education, Faculty of Medicine, University of Colombo, Sri Lanka.

Email:karunathilake@hotmail.com
The advancement of Medical Education in this setting through curricular innovation is a seminal moment for many disciplines in medicine. These are challenging times for low to middle-income countries due to financial constraints coupled with a lack of human and infrastructural resources (Karunathilake, 2017). However, in this backdrop, Sri Lankan Medical Faculties have specially weathered the storm and have managed to continue the academic programmes while overcoming challenges posted by resource constraints. There are many lessons to be learned from universities spread across the island on how to successfully implement and transform Medical Education from one that is conventional to one that is more digitally enabled.

\section{Making the Transition}

Strong advocacy and guidelines put forth by the University Grants Commission Sri Lanka, enabled a swift transition from traditional learning methods to online learning platforms. A clear institutional strategy was therefore fundamental to making this transition (Bediang et al., 2013). However, it should be emphasized that this was not a mere conversion of the traditional paper-based method to one that is digital (Masic, 2008). During a pandemic such as this, importance had to be given to ensuring the safety of staff and all other stakeholders, which was the premise for closing the medical schools and moving teaching to digital platforms (Sahi, et al., 2020). Programs needed to be implemented and evaluated while migrating the risk of contracting COVID-19 by students and staff members, especially during clinical rotations as they could become a portal of the spread of the infection (Del Rio, \& Malani, 2020). In response to the current needs, many clinical departments have come up with innovative plans to avoid overcrowding during

DOI: http://doi.org/10.4038/seajme.v14i1.241

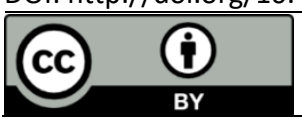

2

(c) SEAJME. This is an Open Access article distributed under the terms of the Creative Commons Attribution License (http://creativecommons.org/licenses/by/4.0/), which permits unrestricted use, distribution, and reproduction in any medium, provided the original author and source are credited 
ward classes. The digital tools that were employed with ease in a low to middle resource setting such as in Sri Lanka were Zoom, through learning networks, voice recorded PowerPoint presentations, and video recorded practical sessions and in certain settings, 3D software.

Donors and alumni networks were utilized to distribute the logistics and provide connections to needy students and minimize difficulties. This also requires ensuring the psychological wellbeing of the students as they navigate through this difficult time and teaching mindfulness to students should also be given precedence. Some universities in Sri Lanka have initiated online extra-curricular activities such as yoga classes, student clubs, and video productions that will positively contribute to the psychological wellbeing of the students.

\section{Advantages}

There has been a shift in mindset. Almost as if it may be a "blessing in disguise". The positive attitudes of the educators and students have made the transition rapid as well as successful. Many have found online teaching to be effective as it enables the availability of remote lecturers who would otherwise travel long distances to deliver lectures especially in universities away from the capital city. Pre-clinical and para clinical teaching up to the fourth year can be completed by electronic mode, which will be approximately $60 \%$ of the content. Online learning has the added advantage of providing easier and more effective access to a wider variety of resources as opposed to traditional teacher-based learning (Mooney \& Bligh, 1997). Today's students of Generation Z are adaptable and are demanding technologydriven education. Online platforms have the advantage of versatility and accessibility. Most students and educators feel that this has improved student participation in online classes where attendance has been nearly $100 \%$. This is rarely seen in traditional face to face traditional lectures. The ability to recall knowledge no longer needs to be rigorously evaluated in a world where information is at your fingertips. Transitioning to a more technology-based teaching method as well as assessment and evaluation methods will also impact the ethos of the future generation of doctors and prepare them to face a world where there is a high digital literacy rate and where their patients will also be well versant with the latest technologies and innovations.

\section{Obstacles and Challenges}

Despite the advantages of the new norm of medical education, there were several challenges in its implementation and deployment. One of the main challenges experienced by most universities is the constraints on the acquisition of hardware, training human resources, availability of low cost/free software solutions coupled with financial difficulties. There are also added demands on educators and students alike to provide a more self-directed personalized learning environment (O'Doherty et al., 2018). In a study conducted by Ranasinghe, et al., (2012), Sri Lankan medical undergraduates reported a low to intermediate level of computer literacy. They identified the need to improve computer literacy among the students by either increasing training in schools or by introducing computer training in the undergraduate program especially as they enter medical school. However, these two options require improvements in infrastructure and many other resources. Internet facilities entailed a huge cost on the university system one of the suggestions made at its inception was to have a partnership with technology providers to facilitate a smooth transition and to uphold the motto of higher education of "leaving no one behind". The locality of the student has also added to problems with connectivity as certain remote areas of the country do not have proper broadband coverage. Conventional teachers are not well versant with online platforms. Skills for decision making under uncertainty as well as soft skills such as empathy must be developed. This is challenging when using purely online-based platforms. Hence as we move forward the need for some face to face interactions in the form of teacher-student or peer to peer, cannot be dismissed.

\section{Way forward}

Adapting to the new norm, therefore, requires several other transformations such as financial, infrastructure, hardware and resource management, etc. This should be achieved by implementing a well thought through plan to utilize existing resources. Digitalization of medical education required a total paradigm shift of teaching and we are yet to make the transition fully. The pandemic has brought to the fore the importance of institutional readiness in making this transition (Frehywot et al., 2013). In a study conducted at the Faculty of Education Colombo, Sri Lanka before the pandemic, the level of readiness to use technology was assessed in pre-service 
teachers and it was found to be satisfactory (Ranawaka et al., 2020).

Owing to the novelty of this experience both the staff and the students will benefit immensely from training programs on the utilization of the available facilities and different online teaching tools. E-learning adaptation is to thus ensure the alignment of new tools to the educational needs and requirements of its users. Additionally, developing soft skills such as ethics, cognitive skills, and empathy should be thought in face-to-face discussions. Changing behavior and attitudes is also challenging when using online platforms. The next critical phase is to incorporate student performance evaluation methods on digital platforms. This is especially challenging when clinical skills need evaluation. Currently, only $25 \%$ of the clinical facilities are being used in clinical teaching. Thus, incorporating and utilizing base hospitals for clinical training programs would help minimize overcrowding during clinical classes and examinations.

In the new norm, ward classes will be converted to small group clinical classes merged with online ward classes and interactive videos. This digital transition will minimize the risk of contracting the virus. Since using real patients when conducting exams is a challenge, the use of simulated patients to assess clinical skills, examination techniques, and communication skills would be the way forward. To reap the benefits of this transition even beyond the pandemic, student-driven active learning should be encouraged. In this light, the accessibility to resources is fundamental to its success (Han et al., 2019). This can be facilitated by incorporating simulation laboratories, with the aid of audio-visual units, computer labs, and libraries. This can also reduce the time for explanation and divert the time to patient-based learning.

\section{Conclusion}

Heralding a conversation on adapting to the new norm of Medical Education is the way forward. As each university had different experiences and put forth ways in which these challenges were met it was a learning endeavor to all. Over the past 150 years' medical education in Sri Lanka has evolved with the changing needs and global trends. Educational reforms should be supported by a national dialogue, institutional leadership, and a professionalized medical education workforce. As a profession, we should all encourage and guide our future students and trainees to thrive in this brave new world.

\section{Note}

This is a perspective of the historical dialogue conducted by the Sri Lanka Medical Association with the participation of the deans of all state medical faculties. This discussion on the present and the future directive of medical education amidst adapting to the new norm of post-COVID-19 was held with the participation of all the Deans of 11 state medical faculties OF Sri Lanka; Colombo, Sri Jayawardhanapura, Peradeniya, Ragama, Sabaragamuwa, Jaffna, Eastern University, Karapitiya, Ruhuna Wayamba, and Kothalawala Defence University.

\section{References}

Bediang, G., Stoll, B., Geissbuhler, A., Klohn, A.M., Stuckelberger, A., Nko'o, S. \& Chastonay, P. (2013) Computer literacy and E-learning Perception in Cameroon: the Case of Yaounde Faculty of Medicine and Biomedical Sciences. BMC Medical Education, 13, 1, pp.57.

Del Rio, C. \& Malani, P.N. (2020) 2019 Novel Coronavirus-Important Information for Clinicians. Jama, 323, 11, pp.1039-1040.

Frehywot, S., Vovides, Y., Talib, Z., Mikhail, N., Ross, H., Wohltjen, H., Bedada, S., Korhumel, K., Koumare, A.K. \& Scott, J. (2013) E-learning in Medical Education in Resource Constrained Lowand Middle- Income Countries. Human Resources for Health, 11, 1, pp.4.

Han, E.R., Yeo, S., Kim, M.J., Lee, Y.H., Park, K.H. \& Roh, H. (2019) Medical Education Trends for Future Physicians in the Era of Advanced Technology and Artificial Intelligence: An Integrative Review. BMC Medical Education, 19, 1, pp.460.

Karunathilake, I.M. (2017) Technology Enhanced Learning with Limited Resources-Transforming Limitations into Advantages. South-East Asian Journal of Medical Education, 11, 1.

Masic, I. (2008) E-learning as New Method of Medical Education. Acta Informatica Medica, 16, 2, pp.102.

Mooney, G.A. \& Bligh, J.G. (1997) Information Technology in Medical Education: Current and Future Applications. Postgraduate Medical Journal, 73, 865, pp.701-704. 
O'Doherty, D., Dromey, M., Lougheed, J., Hannigan, A., Last, J. \& McGrath, D. (2018) Barriers and Solutions to Online Learning in Medical Education- An Integrative Review. BMC Medical Education, 18, 1, pp.130.

Ranasinghe, P., Wickramasinghe, S.A., Pieris, W.R., Karunathilake, I. \& Constantine, G.R. (2012) Computer Literacy among First Year Medical Students in a Developing Country: A Cross Sectional Study. BMC Research Notes, 5, 1, pp.504.

Ranawaka, R.A.T.K.G., Ranathunga, Y.S. Sudarvannan, N. \& Karunathilake, I.M. (2020) Readiness for Technology Based Teaching among Undergraduates of Faculty of Education, University of Colombo. South-East Asian Journal of Medical Education, 13, 2.

Rose, S. (2020) Medical Student Education in the Time of COVID-19. Jama, 323, 21, pp. 21312132.

Sahi, P.K., Mishra, D. \& Singh, T. (2020) Medical Education amid the COVID-19 Pandemic. Indian Pediatrics. [E-pub ahead of print] Available at https://www.indianpediatrics.net/COVID29.03.2 020/SA-00181.pdf. 